\title{
Initiating conservation of a newly discovered population of the Endangered hog deer Axis porcinus in Myanmar
}

\author{
Ngwe Lwin, Matthew Linkie, Abishek Harinar, Saw Soe Aung \\ AUng Ko LIN and FranK MOMBERG
}

\begin{abstract}
The unprecedented political and economic reforms taking place in Myanmar offer new opportunities for biodiversity conservation. They also bring new challenges in the form of rapidly growing extractive industry and agriculture sectors that have been weakly regulated and are often unsustainable. The Endangered hog deer Axis porcinus epitomizes many of these conservation challenges, and those facing most deer species in the IndoBurma hotspot. The hog deer has disappeared from large parts of its range as a result of overhunting and intense conversion of its floodplain grassland habitat for agriculture. We report on a population of hog deer that was discovered in the Indawgyi landscape in central Myanmar in 2012. We conducted the first rigorous assessment of a hog deer population in Myanmar using an occupancy sampling protocol, tested the protocol's robustness using a power analysis, and present the results to guide management intervention. The results from our study site revealed widespread occurrence of the species, with high precision. The population map was then used to inform the development of a conservation management zone within a UNESCO Man and Biosphere Reserve around Indawgyi Lake. The importance of this population for the status of the hog deer in Myanmar remains unknown because documentation of the species has been sparse. Our survey protocol could make a significant contribution to addressing this knowledge gap and setting an informed agenda for conservation of the hog deer both nationally and more widely across the Indo-Burma hotspot.
\end{abstract}

Keywords Detection probability, hunting, mammal conservation, occupancy, South-east Asia, ungulate

\footnotetext{
Ngwe Lwin, Saw Soe Aung, Aung Ko Lin and Frank Momberg Fauna \& Flora International, Yangon, Myanmar

MATTHEW LinKIE* (Corresponding author) Fauna \& Flora International, Singapore 247672, Singapore

Abishek Harihar Panthera, New York, USA, and Nature Conservation Foundation, Mysore, India

${ }^{*}$ Current address: Wildlife Conservation Society (WCS), Indonesia Program, Bogor, Indonesia. Email mlinkie@wcs.org

Received 13 February 2016. Revision requested 23 May 2016

Accepted 23 June 2016. First published online 21 October 2016.
}

\section{Introduction}

F or decades much of Myanmar has been inaccessible to conservation organizations because of political instability and civil unrest. International sanctions have limited investment in government infrastructure and institutional development, including the Forestry Department, which is the country's leading agency for biodiversity conservation (Rao et al., 2013). However, since 2012 Myanmar has undertaken sweeping political and economic reforms aimed at giving foreign organizations access to the country, creating political stability and decreasing government control of the private sector (Schmidt, 2012). This comes at a time when significant attention is also being focused on Myanmar for its role as a major supply hub for illegal wildlife trade in Asia (Shepherd \& Nijman, 2008; Nijman \& Shepherd, 2015).

Myanmar remains rich in wildlife and other natural resources but has long and porous international borders that are poorly enforced or equipped to tackle illegal wildlife trade. Furthermore, overexploitation by poorly regulated mining and logging industries, subsistence hunting, and conversion of floodplains and grasslands to rice fields have depressed already stressed wildlife populations (Rao et al., 2013). These threats have had a collective, although unquantified, impact on the hog deer, which in many ways epitomizes the conservation challenges facing wildlife in Myanmar.

The hog deer's habitat preference for grassland in close proximity to wetlands often puts it in competition with farmers wishing to expand rice fields (Dhungel \& O'Gara, 1991). It is also hunted for its meat. Over the past 2 decades a once widespread species ranging from the Himalayan foothills in Pakistan, Nepal and India to mainland South-east Asia has declined by $>90 \%$ within its South-east Asian range. This includes its complete disappearance from Thailand, Laos PDR and Viet Nam (Timmins et al., 2015a). In Myanmar this once abundant species has been reduced to small, isolated populations (Evans, 1902; Timmins et al., 2015a) and there is a lack of reliable, or even current, population data for the hog deer, as for most other cervids and medium- or large-bodied mammals in general. Thus, the news of the discovery of a hog deer population in Myanmar by Fauna \& Flora International in 2012 was encouraging.

Preliminary field surveys in northern Myanmar recorded the hog deer, using camera traps placed in grassland on the 
eastern shore of Indawgyi Lake, the third largest freshwater lake in mainland South-east Asia. Based on these records a conservation project was launched to produce a site action plan, form community conservation groups to define a hog deer protection zone with village no-hunting agreements, and increase awareness amongst stakeholders of the species' plight. The first important step was to collect reliable data to gain an understanding of the hog deer's population status and threats to the species in the Indawgyi area, which would also provide a baseline for monitoring subsequent project intervention. Thus, the aims of this study were to (1) design and pilot a new hog deer sampling protocol using detection/non-detection surveys, (2) conduct the first scientifically defensible population assessment of the hog deer in Myanmar based on the species' occupancy, and (3) determine future sampling design parameters.

\section{Methods}

\section{Field methods}

From preliminary field surveys conducted in 2011 and 2012 in the northern state of Kachin the putative boundaries of hog deer distribution in the Indawgyi landscape were identified based on suitable habitat, and used to demarcate a study area of $90 \mathrm{~km}^{2}$ (Fig. 1). This study area is characterized by grassland located between the forested watershed hills in Indawgyi Reserve Forest and Indawgyi Lake. Several small creeks flow through the grassland plain, and there are patches of paddy fields in these communal lands.

In Myanmar the hog deer falls under the protection of wildlife and protected areas law 6/1994. The preliminary field surveys, camera trapping and interviews with the local community indicated that the hog deer is solitary, and no herds were recorded. However, in Nepal hog deer have been observed congregating during the fawning season or to forage on new shoot growth stimulated by anthropogenic burning of grasslands (Dhungel \& O'Gara, 1991). An individual's home range is estimated to be $0.5-0.8 \mathrm{~km}^{2}$ (Dhungel \& O'Gara, 1991; Odden et al., 2005). To measure species occupancy the study area was divided into 90 sampling units of $1 \times 1 \mathrm{~km}$, which should be sufficient to encompass an individual's home range.

From a possible selection of 90 grid cells and considering available field resources, 44 cells were selected at random for sampling, using a geographical information system (GIS). Field surveys were conducted during 2-20 May 2014, in the dry season, when it is easier to encounter hog deer sign. A two-person team, consisting of an experienced field biologist and a local guide, surveyed each grid cell for a set sampling effort of 2 hours per cell. To increase detection probability within a cell, the team specifically targeted locations where sign was most likely to be encountered (e.g. animal trails, grasslands and paddy fields). Hog deer sign comprised hoof prints and pellets, which are unmistakable as no other similar deer or livestock species are known to live in this area. Red muntjac Muntiacus vaginalis and sambar Rusa unicolor live outside the study area, in a nearby forest reserve.

Within a grid cell, detection (1) or non-detection (o) of hog deer sign was recorded at four 30-minute intervals (sampling occasions). These replicates are considered to be spatial because the team tried to maintain a similar pace $\left(<_{1} \mathrm{~km}\right.$ per hour) in each cell and avoid overlapping with previously surveyed replicates, by not walking over a previously walked trail within the same grid cell. For each replicate the team recorded whether surveys were conducted off trail (o) or on footpaths or bullock cart paths (1), as well as the dominant habitat type (tall grassland (elephant grass); grassland; burnt grassland; agricultural field, not planted; or agriculture field, planted), all of which could influence species detection probability. It did not rain during surveys, so the influence of this factor was not considered. Direct observations of hog deer hunting and recent burning were recorded seperately for each grid cell.

\section{Data analysis}

A spatial database was constructed for the sampling grid based on three site covariates: mean proximity to nearest village (Village), mean proximity to river or lake (Water), and evidence of recent burning (Burn; denoted as burnt (1) or not burnt (o)). Village and river data obtained from Myanmar Survey Department 1:50.00o topographic maps from 2005 were standardized using a logarithmic transformation. Sampling covariates were compiled along the surveys to denote trail/no trail and the dominant habitat type in each sampling replicate, which were constructed as categorical covariates for both.

Hog deer occupancy $(\psi)$ was estimated using models that account for imperfect species detection (MacKenzie et al., 2006). The occupancy status of grid cells was assumed to remain closed (i.e. constant) during the 2-hour sampling period. As the detection/non-detection sequence of hog deer sign was collected during four consecutive 30-minute sampling occasions per grid cell, a first order Markov process model was used to estimate the probability of hog deer occurrence (Hines et al., 2010). This model accounts explicitly for the potential dependence in detecting signs on consecutive occasions by estimating two segment-level occupancy parameters $\left(\theta\right.$ and $\left.\theta^{\prime}\right)$ and the probability of detecting signs (P) conditional on segment-level occupancy. However, to test for the presence of spatial nonindependence among replicates the constant model $\psi(),. \theta$ (.), $\theta^{\prime}(),. \mathrm{P}(),. \theta \pi($.$) (Hines et al., 2010) was compared to a con-$ stant single-season model, $\psi($.),P(.) (MacKenzie et al., 2002). Candidate models were compared using Akaike's 


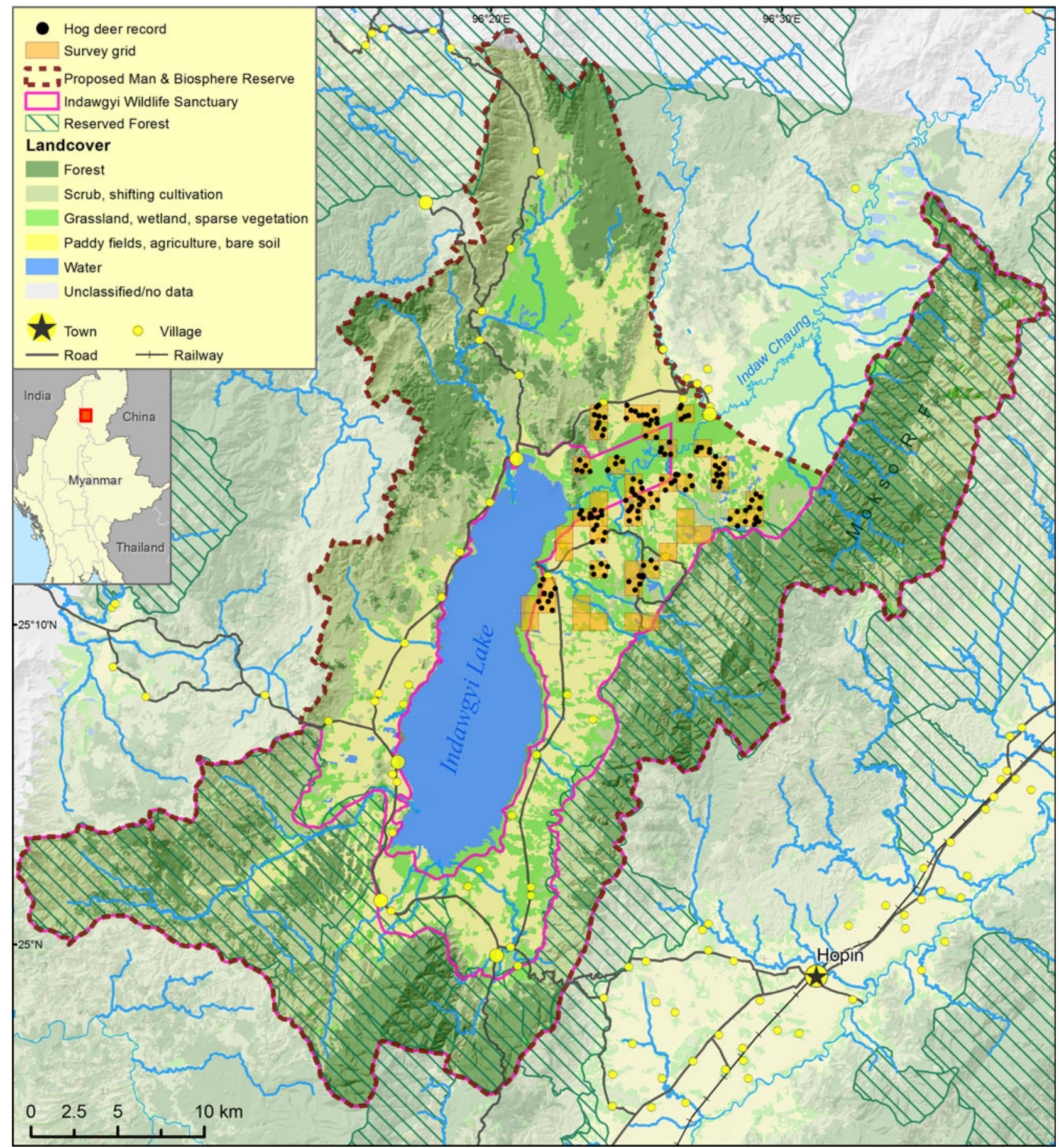

FIG. 1 Habitat of a newly discovered population of hog deer Axis porcinus in the Indawgyi landscape of northern Myanmar, with the survey grid and the locations where hog deer were recorded.

information criterion corrected for small sample sizes (AICc; Burnham \& Anderson, 2002). All analyses were carried out in PRESENCE v. 8.2 (Hines, 2006).

When choosing between a model that explicitly accounted for spatial dependence (Hines et al., 2010) and one that did not (MacKenzie et al., 2002), a two-step modelling approach was used to test the effects of the covariates. Initially, the probability of detecting a sign, where $\mathrm{P}$ was either assumed to be constant or allowed to vary with individual or additively combined covariates, was modelled, with $\psi$ held in a general form for each model. After incorporating covariates influencing detection probability with the greatest Akaike weight $\left(w_{i}\right)$, the influence of spatial covariates on occupancy was assessed in the second step of the analysis. Here $\psi$ was either assumed to be constant or allowed to vary with individual or additively combined covariates. 
TABLE 1 Effect of covariates on detection probability $(\hat{\mathrm{P}})$ of the hog deer Axis porcinus in the Indawgyi landscape of northern Myanmar (Fig. 1).

\begin{tabular}{|c|c|c|c|c|c|}
\hline Model ID & Model description & No. of parameters & $\Delta \mathrm{AICc}^{1}$ & Akaike weight & $-2 \mathrm{~L}^{2}$ \\
\hline M.1.1 & $\psi($ Burn + Water + Village $) \mathrm{P}($ Habitat $)$ & 9 & 0.00 & 0.7377 & 180.02 \\
\hline M.1.2 & $\psi($ Burn + Water + Village $) \mathrm{P}($ Habitat + Burn $)$ & 10 & 3.00 & 0.1644 & 179.65 \\
\hline M.1.3 & $\psi($ Burn + Water + Village $) \mathrm{P}($ Habitat + Burn + Trail $)$ & 11 & 4.66 & 0.0719 & 177.72 \\
\hline M.1.4 & $\psi($ Burn + Water + Village $) \mathrm{P}($ Habitat + Trail $)$ & 10 & 6.70 & 0.0258 & 183.35 \\
\hline M.1.5 & $\psi($ Burn + Water + Village $) \mathrm{P}($ Burn + Trail $)$ & 7 & 18.32 & 0.0001 & 204.52 \\
\hline M.1.6 & $\psi($ Burn + Water + Village $) \mathrm{P}($ Burn $)$ & 6 & 19.28 & 0 & 208.32 \\
\hline M.1.7 & $\psi($ Burn + Water + Village $) \mathrm{P}($ Trail $)$ & 6 & 20.15 & 0 & 209.19 \\
\hline M.1.8 & $\psi($ Burn + Water + Village $) \mathrm{P}()$. & 5 & 20.47 & 0 & 212.21 \\
\hline M.1.9 & $\psi(.) \mathrm{P}()$. & 2 & 24.71 & 0 & 223.73 \\
\hline M.1.10 & $\psi(.) \theta_{0}(.) \theta^{\prime}(.) \mathrm{P}(.) \theta_{0} \pi()$. & 5 & 27.54 & 0 & 221.28 \\
\hline
\end{tabular}

${ }^{1} \triangle \mathrm{AICc}$ is the difference between each model's AICc and the AICc of the top-ranking model.

${ }^{2} \mathrm{~L}$ is the maximum log-likelihood.

\section{Power analysis}

Survey design recommendations were derived based on the $\psi$ and $\mathrm{P}$ estimates obtained from the field study. Where detection probabilities varied depending on survey conditions, the mean of these probabilities was used in calculations. Firstly, the number of survey visits $(K)$ required to determine species presence at an occupied site with a specified probability was investigated. The probability of detecting the species at an occupied site in at least one of the visits is $\mathrm{P}^{\star}=1-(1-\mathrm{P})^{K}$, where $\mathrm{P}$ is the mean detection probability on any one visit. From this expression the number of visits $(K)$ required to achieve a given desired $\mathrm{P}^{*}$ (0.95) was derived as $K=\log \left(1-\mathrm{P}^{*}\right) / \log (1-\mathrm{P})$ (McArdle, 1990; Kéry, 2002; Pellet \& Schmidt, 2005).

Next, variations in the survey design that facilitated the detection of changes in hog deer occupancy were assessed. The assessments were based on the occupancy and detection probability estimates from the study data set and assumed a standard single-season, single-species sampling design in which $S$ sites were sampled $K$ repeated times (where $K$ was determined to achieve $\mathrm{P}^{\star}=0.95$ ). Based on the number of replicates (in our case, the number of successive $30 \mathrm{mi}-$ nute surveys), the number of sampling sites needed to detect a change in occupancy rate between two surveys for a given power given an actual proportional change, $R$ (effect size), was calculated. Six effect sizes $(R=5,10,20$, $30,40$ and $50 \%)$ at a significance level $\alpha=0.05$ were assessed under the constraint that the total number of sites $(S)$ that could be surveyed was 90 (i.e. $90 \times 1 \mathrm{~km}^{2}$ grid cells identified as being within the putative boundaries of hog deer distribution in the Indawgyi landscape). All simulations were implemented using $R$ code developed by Guillera-Arroita \& Lahoz-Monfort (2012).

\section{Results}

The 44 sampling units were surveyed for a combined effort of 87.5 hours, with $2-3$ grid cells completed each day. Hog

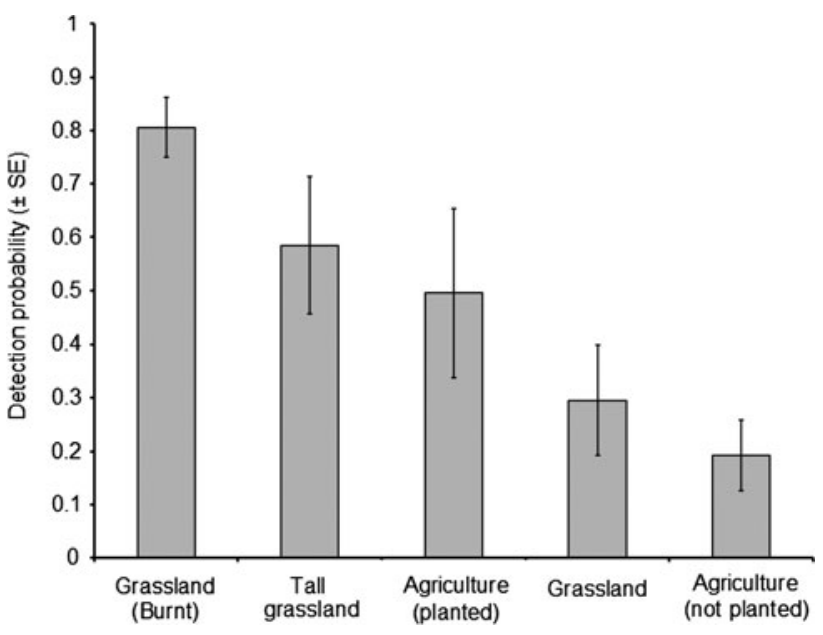

FIG. 2 Mean probability of detection $( \pm S E)$ of hog deer in various habitat types.

deer signs were detected on 73 of 175 sampling occasions and in 32 of 44 sampling units, producing a naïve occupancy estimate of 0.727 .

Detecting hog deer signs Investigating the covariates that influenced the probability of detecting hog deer signs we found little support for spatial dependency in detection resulting from a study design based on four consecutive 30-minute replicates. The Markovian detection model (M.1.10) had the lowest ranking in comparison to a constant single-season model (M.1.9; Table 1). Further examination of the two segment-level occupancy parameters $\left(\theta\right.$ and $\left.\theta^{\prime}\right)$ highlighted non-significant dependency $\left(\theta_{0}=0.310\right.$, 95\% CI 0.147-0.540; $\theta^{\prime}=0.610,95 \%$ CI o.481-0.725). Hog deer detection was strongly correlated with habitat type (M1.1) and there was a large difference between this model and the constant model $(\triangle \mathrm{AICc}=24.71)$. Across the model set, detection of signs was most strongly influenced by habitat (AICc $\left.w_{i}=0.99\right)$ in comparison to burning (AICc $w_{i}=0.23$ ) or trail type (AICc $\left.w_{i}=0.09\right)$. Among the habitat types, the 
TABLE 2 Hog deer occupancy $(\hat{\psi})$ estimates obtained from the best model for the Indawgyi landscape of northern Myanmar (Fig. 1).

\begin{tabular}{|c|c|c|c|c|c|}
\hline Model ID & Model description & No. of parameters & $\Delta \mathrm{AICc}^{1}$ & Akaike weight & $-2 \mathrm{~L}^{2}$ \\
\hline M.2.1 & $\psi($ Water $) \mathrm{P}($ Habitat $)$ & 7 & 0.00 & 0.3017 & 181.66 \\
\hline M.2.2 & $\psi(.) \mathrm{P}($ Habitat $)$ & 6 & 0.50 & 0.2351 & 185.00 \\
\hline M.2.3 & $\psi($ Water + Burn $) \mathrm{P}($ Habitat $)$ & 8 & 1.53 & 0.1402 & 180.19 \\
\hline M.2.4 & $\psi($ Burn $) \mathrm{P}($ Habitat $)$ & 7 & 1.84 & 0.1202 & 183.50 \\
\hline M.2.5 & $\psi($ Village $) \mathrm{P}($ Habitat $)$ & 8 & 2.18 & 0.1014 & 183.84 \\
\hline M.2.6 & $\psi($ Water + Village $) \mathrm{P}($ Habitat $)$ & 7 & 2.93 & 0.0696 & 181.59 \\
\hline M.2.7 & $\psi($ Burn + Water + Village $) \mathrm{P}($ Habitat $)$ & 9 & 4.54 & 0.0311 & 180.02 \\
\hline M.2.8 & $\psi($ Village + Burn $) \mathrm{P}($ Habitat $)$ & 8 & 12.25 & 0.0007 & 190.91 \\
\hline
\end{tabular}

${ }^{1} \triangle \mathrm{AICc}$ is the difference between each model's AICc and the AICc of the top-ranking model.

${ }^{2} \mathrm{~L}$ is the maximum log-likelihood.

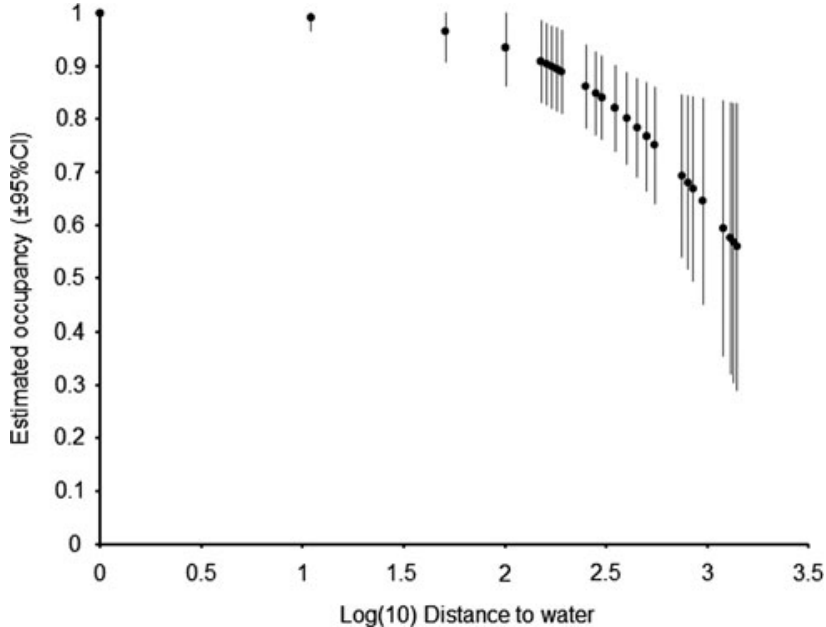

FIG. 3 Estimated relationship between predicted hog deer occupancy and distance to water. The vertical lines represent $95 \%$ confidence intervals.

probability of detecting hog deer sign (given presence) was highest in burnt grassland (Fig. 2).

Hog deer occupancy No sign of hunting of hog deer using firearms was encountered during field surveys. The covariate analysis revealed that species occupancy was higher in habitat closer to water $\left(\hat{\beta}_{\text {water }}=-2.12 \pm \mathrm{SE} 1.70\right.$; M2.1; Table 2, Fig. 3). There was also an effect from human activities, with a higher hog deer occupancy in recently burnt sites $\left(\hat{\beta}_{\text {burnt }}=1.38 \pm\right.$ SE 0.06$)$ and sites further from villages $\left(\hat{\beta}_{\text {village }}=0.31 \pm \mathrm{SE}\right.$ 0.06). The summed model weights for each factor with respect to hog deer occupancy were as follows: distance to water (53.4\%), recent burning (29.2\%) and distance to village (20.3\%). The model averaged occupancy $\hat{\psi}$ was $0.83 \pm$ SE 1.3 .

Power analysis According to the estimated mean detection probability $(\hat{P}=0.47 \pm \mathrm{SE} 0.10)$ the number of replicates (30-minute survey intervals) required to determine hog deer presence at an occupied site with

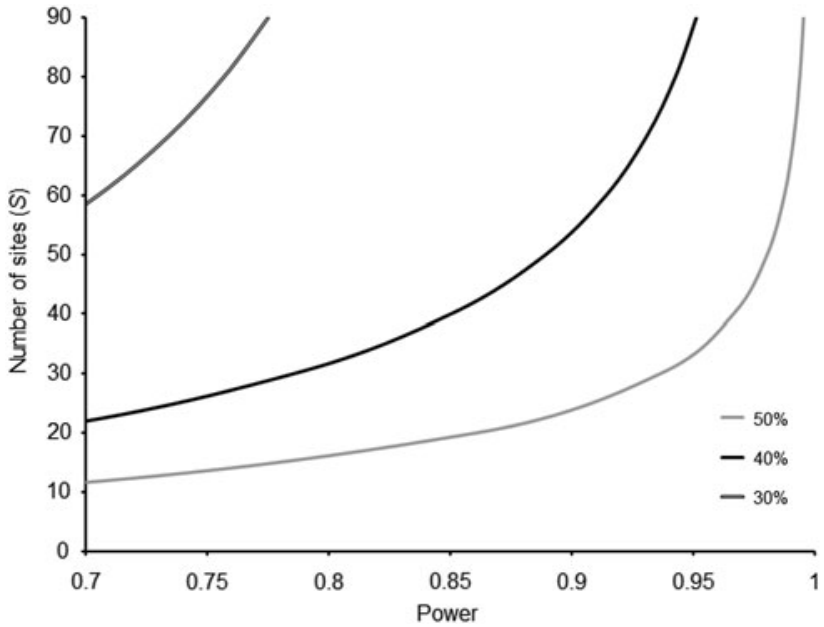

FIG. 4 Number of sampling sites needed to detect a change in occupancy rate with varying effect size at a significance level of $\alpha=0.05$.

$95 \%$ confidence was five. This corresponds to a survey effort of 2.5 hours per grid cell, rather than the 2-hour field surveys conducted. Based on the model-averaged occupancy $(\hat{\psi}=0.82 \pm$ SE 0.13$)$ and detection probability $(\hat{P}=0.47 \pm$ SE 0.10) estimated from the field data, the number of sites that would be required in a future survey design to detect a change in occupancy varied considerably under different scenarios (Fig. 4). These results revealed the study area supporting a maximum of 90 sites and surveyed over five occasions would not be able to detect changes in occupancy of 5,10 or $20 \%$ with a power of 0.7 . At least 60 , 30 and 20 sites would need to be sampled to detect changes in occupancy of 30,40 or $50 \%$, respectively, with a power of $>0.7$.

\section{Discussion}

Several deer species have undergone an overall decline across their mainland South-east Asian range, most notably sambar, hog deer and Eld's deer Rucervus eldii (Gray et al., 
2015; Timmins et al., 2015a,b). Yet our findings indicate that the hog deer in our Myanmar study area have not followed this trend. The sampling protocol developed and its successful implementation proved to be robust. More importantly, our study shed light on a previously little known hog deer population in Myanmar by revealing a high occupancy across its putative habitat, and this information was used to influence conservation planning directly. This is welcome news for a species that is under immense pressure. Security concerns notwithstanding, we recommend using this rapid survey technique across the wider Indawgyi landscape and mapping the status of the hog deer elsewhere in Myanmar, especially in areas of tall grassland and riparian forest that may have been overlooked previously.

\section{Sampling protocol}

In tropical Asia the applicability of occupancy survey techniques for conducting range-wide assessments has been demonstrated for entire species (Asian tapir Tapirus indicus), subspecies (Sumatran tiger Panthera tigris sumatrae) and populations (sun bear Helarctos malayanus, which was categorized as Data Deficient at the time; Linkie et al., 2007, 2013; Wibisono et al., 2011). Our application of this technique to the hog deer yielded precise estimates of occupancy and detection probability. Furthermore, the sampling protocol required minimal training for a team with no prior experience of conducting surveys within a capture-recapture framework, although training in identification of species sign, especially where sympatric species occur, may be challenging for an inexperienced team. The baseline results are promising, and the power analysis identified where the protocol should be refined.

A simple modification to increase confidence in confirming the presence of hog deer would be to increase the survey effort from 2 to 2.5 hours per grid cell. A more challenging modification would be to increase the number of survey sites, to detect a significant change in population trend. Based on the current sampling framework and its results, a change in occupancy would only be detected if it were at least $\pm 30 \%$. To improve the detection level would require increasing the number of sampling sites beyond the current range maximum of 90 cells. This finding has important implications for similar studies in tropical landscapes where the extent of habitat left to monitor is small, especially regarding the need to understand the occupancy dynamics of colonization and extinction within grid cells. As a caveat, grid cell size may need to vary based on varying habitat quality across the hog deer's range to ensure that occupancy is being measured, and where hog deer live in extensively flooded landscapes rapid surveys should be conducted in both wet and dry seasons to avoid possible sampling biases associated with seasonal movements.

\section{Hog deer occupancy}

The widespread occurrence of the hog deer in our study area raises several points for consideration. Firstly, without a historical baseline from the wider Indawgyi landscape we cannot fully rule out that the current population is in fact a remant of one that once extended across a larger range, and is therefore declining. We recommend expanding future surveys beyond the putative range, which was identified through preliminary field surveys, including interviews with the local community. Not only is this predicted to improve statistical rigour in measuring population trends, it would also reduce the likelihood of individuals being missed and excluded from subsequent conservation planning. There is a seemingly suitable grassland habitat by the west side of Indawgyi Lake but it was not possible to survey there because of security concerns.

In the Indawgyi landscape hog deer occupancy was higher in habitat that was closer to water. This finding fits with the species' known preference for tall grassland and riparian forest, which is associated with the floodplains of large rivers and lakes (Odden et al., 2005). Monsoonal flooding, as well as anthropogenic burning of grass (for which we found a positive and significant correlation with hog deer occupancy), would stimulate the growth of young and edible shoots, thereby increasing food availability for hog deer, as found for the chital Axis axis (Moe \& Wegge, 1997). Although the results suggest that burning was not detrimental to the hog deer (e.g. through reducing hiding cover), the species did exhibit a tendency to avoid villages. This may have been to evade a threat not quantified in this study, such as areas of higher human activity in Pakistan that were completely avoided by hog deer (Arshad et al., 2012).

\section{Threats to the hog deer}

Hog deer may have thrived in the Indawgyi landscape because of lower levels of threats that have been identified as being important elsewhere, primarily the conversion of floodplain grassland to rice paddy, attacks by domestic dogs, the use of poisons to protect crops from wild herbivores, and hunting for wild meat using snares and guns. Other threats were absent; for example, competition from livestock grazing, competition with other wildlife (e.g. elephant, sambar, gaur Bos gaurus) for grazing, and the presence of large felid predators, such as the tiger and leopard Panthera pardus (Bhowmik, 2002). Furthermore, informal interviews with two local hunters revealed that home-made guns were typically used in the past to shoot hog deer, and also spears or knives, particularly at night in paddy fields during the rainy season, when it is easier to creep up close. However, these interviews also revealed that hog deer hunting was considered to be minimal both in the past and at present. Nonetheless, during a routine project 
site visit in 2012 the survey team found a hunting platform in the grassland, and the occupancy team would have found it difficult to detect signs of hunting with guns during surveys. It is difficult to quantify the threat posed by hunting, and we recommend a fuller assessment; however, the widepsread occupancy of hog deer recorded suggests that the level of threat is not high in our study area.

The absence of a covariate for the presence of dogs, as a proxy for hunting, may be a limitation in our study. We used distance to village as a proxy for human disturbance (a commonly used technique in hunting and deforestation studies in the tropics) and this should have partly controlled for the presence of dogs, if indeed they had an effect. Thus, whereas we cannot directly disprove the relationship between hog deer and the presence of dogs, the widespread hog deer occupancy ( $83 \%$ of the study area) suggests that hunting was not influential. If dogs were critically important and hunting was high then the widespread occupancy pattern we recorded for this threatened species would not have been found. The major threat to the hog deer population is most likely to be the conversion of grasslands for agricultural use, primarily on the banks of the Indaw Chaung river and in the mosaic of grasslands and agricultural fields between the river and Mokso Reserved Forest. As part of the ongoing management planning for Indawgyi wildlife sanctuary, as well as through the designation and zonation of the Indawgyi biosphere reserve, efforts to limit new conversion, especially between Indaw Chaung and Mokso Reserved Forest, will be prioritized through core conservation zones and/or restricted buffer zones for livestock grazing only. These would then be demarcated and managed through collaborative patrolling and law enforcement. Fauna \& Flora International is working with the Nature Conservation Department on the zonation of a wildlife sanctuary, in part based on the results of the hog deer survey, which foresees the designation of core and buffer zones.

In Myanmar the terrestrial protected area system has been designed primarily to support the conservation management of the country's biodiversity-rich rainforests, although many of the protected areas have yet to be officially gazetted (Myint Aung, 2007; Rao et al., 2013). The government's lack of awareness of the plight of grassland ecosystems coupled with demands to clear these spaces for agriculture means that little actual or presumed hog deer habitat is formally protected. As noted in the 2008 and 2014 IUCN Red List assessments, reliable information on the range and population status of the hog deer in Myanmar is lacking and prevents the formulation of a national species strategy (Timmins et al., 2015a). The rapid and robust occupancy survey protocol applied in our study provides the approach for conducting such a widespread national survey, such as in Hukaung Valley (one of the largest floodplains in tropical Asia) and Pidaung Wildlife Sanctuary (once considered important for hog deer but which has undergone significant habitat conversion). However, our sampling protocol could be extended to include other little-known deer species, such as sambar and Eld's deer, in South-east Asia.

\section{Acknowledgements}

We thank Patrick Oswald for GIS support, Sarah Brook for sharing information on the hog deer, the Myanmar Forestry Department for survey permission, and the Conservation Leadership Programme and the Helmsley Charitable Fund for funding the work.

\section{Author contributions}

ML, NL and FM conceived and designed the study. NL, SSA and AKL conducted the fieldwork. AH analysed the data. ML, NL, AH and FM wrote the article.

\section{References}

Arshad, M., Ullah, I., Chaudhry, M.J.I. \& Khan, N.U.H. (2012) Estimating hog deer Axis porcinus population in the riverine forest of Taunsa Barrage Wildlife Sanctuary, Punjab, Pakistan. Records: Zoological Survey of Pakistan, 21, 25-28.

Bношмік, M.K. (2002) The causes of decline of hog deer (Axis porcinus) in protected areas of Himalayan West Bengal. Zoos' Print Journal, 17, 858-860.

Burnham, K.P. \& Anderson, D.R. (2002) Model Selection and Multimodel Inference: A Practical Information-Theoretic Approach. Second edition. Springer-Verlag, New York, USA.

Dhungel, S.K. \& O'GARA, B.W. (1991) Ecology of the hog deer in Royal Chitwan National Park, Nepal. Wildlife Monographs, 119, 3-40.

Evans, G.H. (1902) Notes on the hog deer in Burma. Journal of the Bombay Natural History Society, 14, 310-315.

Gray, T.N.E., Brook, S.M., Mcshea, W.J., Mahood, S., Ranjitsingh, M.K., Miyunt, A. et al. (2015) Rucervus eldii. The IUCN Red List of Threatened Species 2015: e.T4265A22166803. Http://dx.doi.org/10.2305/IUCN.UK.2015-2.RLTS.T4265A22166803. en [accessed 29 May 2016].

Guillera-Arroita, G. \& Lahoz-Monfort, J.J. (2012) Designing studies to detect differences in species occupancy: power analysis under imperfect detection. Methods in Ecology and Evolution, 3, $860-869$.

HiNES (2006) PRESENCE2: software to estimate patch occupancy and related parameters. USGS Patuxent Wildlife Research Center. Http://www.mbr-pwrc.usgs.gov/software/presence.html [accessed 19 September 2016].

Hines, J.E., Nichols, J.D., Royle, J.A., Mackenzie, D.I., Gopalaswamy, A.M., Kumar, N.S. \& Karanth, K.U. (2010) Tigers on trails: occupancy modeling for cluster sampling. Ecological Applications, 20, 1456-1466.

Kéry, M. (2002) Inferring the absence of a species: a case study of snakes. The Journal of Wildlife Management, 66, 330-338.

Linkie, M., Dinata, Y., Nugroho, A. \& Achmad Haidir, I. (2007) Estimating occupancy of a Data Deficient mammalian species living in tropical rainforests: sun bears in the Kerinci Seblat region, Sumatra. Biological Conservation, 137, 20-27. 
Linkie, M., Guillera-Arroita, G., Smith, J., Ario, A., Bertagnolio, G., Cheong, F. et al. (2013) Cryptic mammals caught on camera: assessing the utility of range wide camera trap data for conserving the endangered Asian tapir. Biological Conservation, 162, 107-115.

Mackenzie, D.I., Nichols, J.D., Lachman, G.B. Droege, S., Royle, J.A. \& LANGTimm, C.A. (2002) Estimating site occupancy rates when detection probabilities are less than one. Ecology, 83, 22482255.

Mackenzie, D.I., Nichols, J.D., Royle, J.A., Pollock, K.H., B Ailey, L.L. \& Hines, J.E. (2006) Occupancy Estimation and Modeling: Inferring Patterns and Dynamics of Species Occurrence. Academic Press, New York, USA.

MCARdLe, B.H. (1990) When are rare species not there? Oikos, 57, 276-277.

Moe, S.R. \& Wegge, P. (1997) The effects of cutting and burning on grass quality and axis deer (Axis axis) use of grassland in lowland Nepal. Journal of Tropical Ecology, 13, 279-292.

Myint Aung, U. (2007) Policy and practice in Myanmar's protected area system. Journal of Environmental Management, 84, 188-203.

Nijman, V. \& Shepherd, C.R. (2015) Trade in tigers and other wild cats in Mong La and Tachilek, Myanmar-A tale of two border towns. Biological Conservation, 182, 1-7.

Odden, M., Wegge, P. \& StoraAs, T. (2005) Hog deer Axis porcinus need threatened tallgrass floodplains: a study of habitat selection in lowland Nepal. Animal Conservation, 8, 99-104.

Pellet, J. \& Schmidt, B.R. (2005) Monitoring distributions using call surveys: estimating site occupancy, detection probabilities and inferring absence. Biological Conservation, 123, 27-35.

Rao, M., Htun, S., Platt, S.G., Tizard, R., Poole, C., Myint, T. \& WATson, J.E.M. (2013) Biodiversity conservation in a changing climate: a review of threats and implications for conservation planning in Myanmar. Ambio, 42, 789-804.
Schmidt, C. (2012) As isolation ends, Myanmar faces new ecological risks. Science, 337, 796-797.

Shepherd, C.R. \& Nijman, V. (2008) The trade in bear parts from Myanmar: an illustration of the ineffectiveness of enforcement of international wildlife trade regulations. Biodiversity and Conservation, 17, 35-42.

Timmins, R., Duckworth, J.W., Samba Kumar, N., Anwarul Islam, M., Sagar Baral, H., Long, B. \& Maxwell, A. (2015a) Axis porcinus. The IUCN Red List of Threatened Species 2015: e. T41784A22157664. Http://dx.doi.org/10.2305/IUCN.UK.2015-4. RLTS.T41784A22157664.en [accessed 28 May 2016].

Timmins, R., Kawanishi, K., Giman, B., Lynam, A., Chan, B., Steinmetz, R. et al. (2015b) Rusa unicolor. The IUCN Red List of Threatened Species 2015: e.T4179oA85628124 [accessed 29 May 2016].

Wibisono, H.T., Linkie, M., Guillera-Arroita, G., Smith, J.A., Sunarto, Pusparini, W. et al. (2011) Population status of a cryptic top predator: an island-wide assessment of tigers in Sumatran rainforests. PLoS ONE, 6(11), e25931.

\section{Biographical sketches}

NGWE LWIN has been working on conservation projects in Myanmar for 8 years. MAтTHEW Linkie has worked in Asia, mainly on tiger conservation, since 1999. He is the Asia Coordinator for the IUCN Species Survival Commission Wild Pig Specialist Group. A Bishek HARIHAR has worked on tiger conservation in northern India since 2003 and currently works as a tiger population ecologist. S AW Soe Aung coordinates biodiversity monitoring in Myanmar's Tanintharyi landscape. A UNG Ko LIN conducts biodiversity surveys in the Indawgyi and Imawbum areas of northern Myanmar. FrA NK Momberg has worked on the development of conservation projects in Asia since 2000. 